\title{
Formação PNAIC 2014 e os Saberes Docentes de Matemática de um Grupo de Professoras Alfabetizadoras
}

\author{
Formación PNAIC 2014 y los Saberes Docentes de Matemática de un \\ Grupo de Profesoras Alfabetizadoras \\ PNAIC 2014 Training and the Teaching Knowledge of Mathematics of a \\ Group of Literacy Teachers
}

\author{
Sílvia Raquel Islabão da Silveira ${ }^{1}$ \\ Antônio Mauricio Medeiros Alves²
}

\begin{abstract}
Resumo
$\mathrm{O}$ presente artigo refere-se à pesquisa de Mestrado em desenvolvimento no âmbito do Programa de PósGraduação em Educação Matemática da Universidade Federal de Pelotas (UFPel) e tem por objetivo geral identificar os saberes de Matemática de professoras participantes da formação do Pacto Nacional pela Alfabetização na Idade Certa de 2014 - cujo tema central foi a alfabetização Matemática - após essa formação. Os sujeitos da pesquisa compõem um grupo de professoras alfabetizadoras de uma escola pública da rede estadual, participantes do citado projeto de formação continuada. A fim de atender ao objetivo apresentado propôs-se uma pesquisa de cunho qualitativo, do tipo estudo de caso, na qual aponta-se as características desse programa de formação continuada proposto para professoras do ciclo de alfabetização de todo país, especificamente no ano de 2014 e como essa formação ocorreu no âmbito da Universidade Federal de Pelotas. Apresenta uma discussão sobre os saberes docentes de Matemática necessários para o trabalho nos anos iniciais do ensino fundamental, bem como a formação matemática desses sujeitos. Os dados estão sendo produzidos por meio de entrevistas e serão posteriormente analisados considerando como metodologia a Análise Textual Discursiva. Espera-se com essa pesquisa contribuir com a reflexão sobre os impactos desse importante programa de formação continuada, nos saberes mobilizados pelas professoras ao ensinar matemática para as crianças.
\end{abstract}

Palavras-Chave: alfabetização Matemática; formação de professores; PNAIC; saberes docentes

\section{Resumen}

El presente artículo se refiere a la investigación de Maestría en desarrollo en el ámbito del Programa de Postgrado en Educación Matemática de la Universidad Federal de Pelotas (UFPel) y tiene por objetivo general identificar los saberes de Matemáticas de profesoras participantes en la formación del Pacto Nacional por la Alfabetización en la Edad Cuna de 2014 - cuyo tema central fue la alfabetización Matemática - después de esa formación. Los sujetos de la investigación componen un grupo de profesoras alfabetizadoras de una escuela pública de la red estadual, participantes del citado proyecto de formación continuada. A fin de atender al objetivo presentado se propuso una investigación de cuño cualitativo, del tipo estudio de caso, en la que se apunta las características de ese programa de formación continuada propuesto para profesoras del ciclo de alfabetización de todo país, específicamente en el año 2014 y como esa formación ocurrió en el ámbito de la Universidad Federal de Pelotas. Se presenta una discusión sobre los saberes docentes de Matemáticas necesarios para el trabajo en los años iniciales de la enseñanza fundamental, así como la formación matemática de esos sujetos. Los datos están siendo producidos por medio de entrevistas y serán posteriormente analizados considerando como metodología la Análisis textual Discursiva. Se espera con esta investigación contribuir con la reflexión sobre los impactos de ese importante programa de formación continuada, en los saberes movilizados por las maestras al enseñar matemáticas para los niños.

\footnotetext{
${ }^{1}$ Licenciatura Plena em Matemática pela UFPEL; Pelotas; RS; Brasil; silvia_raquel79@ @otmail.com

${ }^{2}$ Doutor em Educação pela Universidade Federal de Pelotas; Pelotas; RS; Brasil; alves.antoniomauricio@gmail.com
} 
Palabras claves: alfabetización matemática; conocimientos docentes; formación de profesores; PNAIC

\begin{abstract}
This article refers to the Master's research in development within the scope of the Postgraduate Program in Mathematical Education of the Federal University of Pelotas (UFPel) and its general objective is to identify the mathematical knowledge of teachers participating in the formation of the National Pact by Literacy in the Right Age of 2014 - whose central theme was Mathematics literacy - after this formation. The research subjects comprise a group of literacy teachers from a public school of the state network, participants in the aforementioned continuing education project. In order to meet the objective presented, a qualitative research was proposed, such as a case study, in which the characteristics of this continuous training program proposed for teachers of the literacy cycle of every country, specifically in the year 2014 and how this training took place within the scope of the Federal University of Pelotas. It presents a discussion about the mathematical teachers' knowledge required for the work in the initial years of elementary school, as well as the mathematical training of these subjects. The data are being produced through interviews and will be further analyzed considering as methodology the Discursive Textual Analysis. It is hoped that this research will contribute to the reflection on the impacts of this important program of continuous formation, in the knowledge mobilized by the teachers when teaching mathematics for the children.
\end{abstract}

Keywords: literacy Mathematics; PNAIC; teacher knowledge; teacher training

\title{
1. Introdução
}

Este trabalho é parte da dissertação de mestrado que está sendo desenvolvida na linha de Ensino e Aprendizagem do Programa de Pós-Graduação em Educação Matemática (PPGEMAT) da Universidade Federal de Pelotas (UFPel) e, também, vinculado ao Grupo de Estudos sobre Educação Matemática nos Anos Iniciais (GEEMAI).

O grupo, cadastrado no Conselho Nacional de Desenvolvimento Científico e Tecnológico (CNPq) desde 2015, vinculado ao Programa de Pós-Graduação em Educação Matemática (PPGECM), tem procurado desenvolver com os pesquisadores a compreensão sobre o ensino de Matemática nos anos iniciais, com seus pressupostos e metodologias, de modo que se favoreçam práticas mais efetivas para esse ensino visando o aprofundamento teórico das questões relevantes ao tema. Preocupa-se, ainda, com pesquisas envolvendo a formação inicial e continuada de professores que ensinam Matemática.

O tema central do projeto é o programa de formação Pacto Nacional pela Alfabetização na Idade Certa (PNAIC), edição 2014, o qual centrou-se na formação continuada na área de Alfabetização Matemática. Para dar conta desse tema, a seguinte questão norteará o estudo: quais as implicações da formação do PNAIC 2014 nos saberes docentes de Matemática de um grupo de professoras alfabetizadoras?

$\mathrm{Na}$ questão proposta identificamos os sujeitos da pesquisa, um grupo de professoras alfabetizadoras, de uma escola estadual da periferia de Pelotas, que participaram da formação oferecida pela equipe UFPel no âmbito do projeto PNAIC, no ano de 2014. Estas 
alfabetizadoras fazem parte do grupo docente da escola onde a primeira autora desse trabalho atua como professora.

O trabalho contempla um estudo sobre os saberes docentes de Matemática necessários às professoras para o trabalho nos anos iniciais do ensino fundamental. Procuramos ainda identificar a formação matemática dos sujeitos da pesquisa.

Quanto à Metodologia, propôs-se uma pesquisa de cunho qualitativo, do tipo estudo de caso, que iniciou pela exploração de documentos referentes ao PNAIC de 2014, contemplando ainda como essa formação ocorreu no âmbito da Universidade Federal de Pelotas. Já os dados estão sendo produzidos por meio de entrevistas e serão posteriormente analisados considerando como metodologia a Análise Textual Discursiva (MORAES e GALIAZZI, 2006).

Espera-se com essa pesquisa, contribuir com a reflexão sobre os impactos desse importante programa de formação continuada, o PNAIC, nos saberes mobilizados pelas professoras ao ensinar matemática para as crianças.

\section{Desenvolvimento}

Nesta secção serão problematizadas as questões centrais que envolvem esse trabalho: a formação de professores, o papel do PNAIC na formação continuada de professores e como o referido programa se desnvolveu no âmbito da Universidade Federal de Pelotas.

Por meio dessa problematização se buscará apresentar um quadro geral da pesquisa em andamento, a qual gerou o presente trabalho.

\subsection{Formação de Professoras que Ensinam Matemática nos Anos Iniciais}

Segundo Curi (2005) a trajetória da formação de professoras que ensinam Matemática nos anos iniciais no Brasil passa por três períodos: o primeiro vai da implantação do Curso Normal até sua extinção, ocorrida com a promulgação da LDBEN 5692/71, o segundo começa quando a referida lei entra em vigor e vai até a promulgação da LDBEN 9394/96, a partir da promulgação desta lei começa o terceiro período que persiste até os dias atuais.

A implantação do Curso Normal no Brasil, data de 15 de outubro de 1827 e possuía como finalidade formar professoras que atuariam nas chamadas escolas das Primeiras Letras. Neste período a preocupação deste curso era com a caligrafia das professoras, os métodos disciplinares que seriam utilizados pelas mesmas com seus alunos e também com a moral e os bons costumes das futuras professoras. Neste curso não havia a preocupação com a formação Matemática (CURI, 2005). 
"Foi em 1931 que apareceu no currículo do Curso Normal, pela primeira vez, uma disciplina com o nome de Matemática, unificando as disciplinas Aritmética e Geometria" (CURI, 2005, p. 47).

Com a promulgação da LDBEN 5692/71, implementa-se o Curso de Magistério a nível de $2^{\circ}$ grau (atual ensino médio) como formador das professoras polivalentes e, também, possibilita as graduandas em Pedagogia fazer a opção pela habilitação magistério e lecionar nas turmas de $1^{\mathrm{a}}$ à $4^{\mathrm{a}}$ séries (hoje anos iniciais) do $1^{\mathrm{o}}$ grau (atual ensino fundamental). Neste momento, tanto o Curso de Magistério, quanto a Pedagogia com habilitação para o magistério, não apresentam uma preocupação com a formação Matemática das alunas. No Curso de Magistério somente no último ano os alunos cursavam disciplinas como Didática da Língua Portuguesa e Didática da Matemática, já nos cursos de Pedagogia apresentavam uma predominância dos Fundamentos da Educação, deixando de lado as didáticas específicas das disciplinas que o futuro professor teria que ensinar (CURI, 2005).

Nos dias atuais, a formação das professoras que ensinam Matemática, também chamados de professoras polivalentes, se dá em nível superior nos cursos de Pedagogia como prevê a LDB 9394/96. Nestes Cursos, geralmente, o tempo destinado à formação Matemática do professor é de uma ou duas disciplinas. Muitos alunos que ingressam no curso de Pedagogia o fazem justamente por durante sua vida escolar apresentaram dificuldades na aprendizagem de Matemática e, então, procuram um curso em que a disciplina praticamente não esteja presente.

Esta situação fica evidente em lermos Curi (2005, p. 150) ao apontar que:

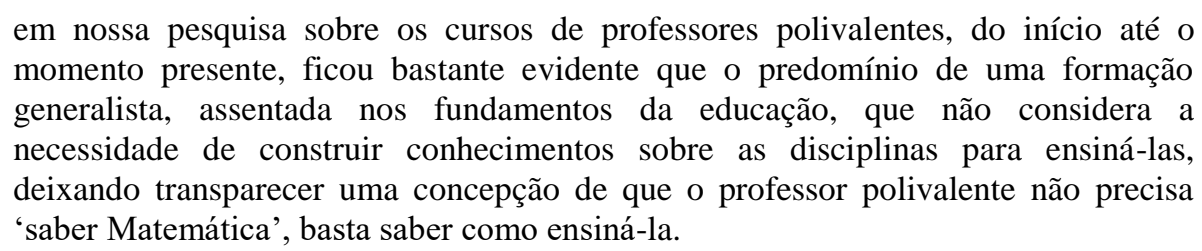

Desse processo de formação, no qual o professor não precisa saber Matemática, mas somente saber como ensiná-la, resulta profissionais que nem sempre dominam os conteúdos matemáticos com os quais irão trabalhar, nem conceitos, nem procedimentos e nem mesmo a linguagem Matemática que deveriam utilizar para ensinar essa disciplina, sendo necessária uma discussão sobre os saberes profissionais dos professores.

Sobre os saberes necessários à docência, Shulman (1986 apud MANRIQUE; ANDRÉ, 2013) sugere que, além dos saberes que as políticas avaliativas levam em consideração - o 
domínio do conteúdo a ser ensinado e o das habilidades puramente pedagógicas - há, um terceiro saber, que integra os outros dois: o conhecimento do conteúdo no ensino.

Segundo o autor são três os saberes fundamentais ao professor: o conhecimento do conteúdo, o conhecimento pedagógico do conteúdo e o conhecimento curricular.

Ou seja, para explicar determinado conteúdo o professor precisa conhecer além dele, precisa dominá-lo e estar aberto aos questionamentos dos alunos, além disso precisa conhecer diversas formas de ensiná-lo, visto que nem todos alunos aprendem da mesma forma. Se o professor não conhece o conteúdo a ser ensinado, certamente interferirá negativamente na aprendizagem de seus alunos, que aceitam como verdades absolutas o que seus professores ensinam.

Shulman (1986), argumenta ainda que esses conhecimentos são efetivamente construídos na prática do professor, ao trabalhar com os alunos em seu cotidiano, o professor se depara com diferentes formas de aprender e ensinar e assim constrói seus saberes na prática.

Por isso, acreditamos que a formação de um professor não é um momento estanque, ela vai desde seu ingresso na educação básica, segue pela sua graduação e deve acontecer o tempo todo com programas de formação continuada e troca com seus pares em reuniões pedagógicas.

\footnotetext{
Os processos de aprender a ensinar, de aprender a ser professor e de desenvolvimento profissional de professores são lentos, iniciam-se antes do espaço formativo dos cursos de licenciatura e se prolongam por toda a vida. A escola e outros espaços de conhecimento são contextos importantes nessa formação. Conhecimentos teóricos diversos assim como aqueles que têm como fonte a experiência pessoal e profissional são objetos de aprendizagem constantes (MIZUKAMI, 2013, p. 214).
}

Dessa forma, compreendemos que os professores se formam muito antes de entrar em um curso de nível médio ou superior, são formados a partir das práticas que seus professores têm, bem como continuam depois que deixam os bancos acadêmicos e entram em uma sala de aula para lecionar. Sua formação é constante, por isso a necessidade de participar de cursos de formação continuada e de que esses sejam ofertados com fácil acesso aos educadores.

Disso decorre a necessidade da formação continuada e o PNAIC foi uma importante política nessa direção.

\subsection{PNAIC e a Formação de Professores}


O Pacto Nacional pela Alfabetização na Idade Certa (PNAIC) foi oficializado através da Portaria $\mathrm{n}^{\mathrm{o}}$ 867, de 04 de julho de 2012, sendo lançado pelo Ministério da Educação (MEC). Este programa é um compromisso entre o Governo Federal, Estados e Municípios a fim de que todas as crianças estejam alfabetizadas, em Língua Portuguesa e Matemática até os 8 anos de idade, ou seja, até o final do terceiro ano do ensino fundamental, no que ficou denominado por Ciclo de Alfabetização.

A preocupação do governo, especificamente com os três primeiros anos do ensino fundamental, advém de que estes formam o Ciclo de Alfabetização, que foi assim instituído, pela resolução $n^{\circ} 7$ de 14 de dezembro de 2010 do Conselho Nacional de Educação (CNE), com a redação dada pela Lei $n^{\circ}$ 9.131/95, no art. 32 da Lei $n^{\circ}$ 9.394/96, na Lei $n^{\circ} 11.274 / 2006$, e com fundamento no Parecer CNE/CEB no 11/2010.

O Programa tinha por objetivo também, reduzir a distorção idade-série da Educação Básica, melhorar o Índice de Desenvolvimento da Educação Básica (IDEB), contribuir para o aperfeiçoamento da formação de professores alfabetizadores, e construir propostas para a definição dos direitos de aprendizagem e desenvolvimento das crianças nos três primeiros anos do Ensino Fundamental.

Para alcançar esses objetivos, as ações do PNAIC foram pensadas em quatro eixos de atuação: formação continuada; materiais didáticos; avaliações; e gestão, controle e mobilização social (BRASIL, 2012). Dentre os materiais didáticos distribuídos no primeiro ano se destacavam os Cadernos de Formação em Linguagem, organizados pelo MEC, que eram enviados às Instituições de Ensino Superior (IES). O MEC distribuiu ainda, para as escolas que aderiram ao Programa, obras pedagógicas complementares aos livros didáticos fornecidos pelo Plano Nacional do Livro Didático (PNLD), jogos pedagógicos e obras de literatura para uso em sala de aula.

A proposta do MEC era criar uma rede de formação de professores, em que a produção e fornecimento do material formativo - cadernos de formação - ficaria ao seu encargo. Esses Cadernos de Formação eram enviados às Instituições de Ensino Superior (IES) que tinham uma equipe composta por Coordenador Geral, Supervisores e Formadores de Ensino. Os Supervisores orientavam os Formadores no planejamento das formações presenciais que fariam com os Orientadores de Ensino (OE), que por sua vez planejavam e executavam as formações com as Professoras Alfabetizadoras (PAs).

Todo este trabalho era voltado para que, ao receber a formação continuada, os professores alfabetizadores pudessem refletir sobre as teorias para melhorar sua prática a fim 
de que os objetivos de alfabetização dos alunos em Língua Portuguesa e Matemática fossem alcançados.

As ações do PNAIC deveriam ser monitoradas pelo coordenador local e a avaliação do Programa se daria pela prova ANA (Avaliação Nacional da Alfabetização) realizada ao final do Ciclo de Alfabetização. Além do acompanhamento realizado por todos os envolvidos na formação através do SISPACTO que integra o Sistema Integrado de Monitoramento, Execução e Controle (SIMEC), o qual pode ser acessado de qualquer computador conectado a internet, desde que a pessoa tenha cadastro como parte integrante do referido programa.

O programa foi pensado para que no ano de 2013, primeiro ano de implantação, fosse dada ênfase na área das linguagens e no ano de 2014, segundo ano de formação, o tema abordado fosse a Alfabetização Matemática. Para isso, a rede colaborativa de formação continuou sendo a mesma, porém foram lançados novos cadernos de formação para dar conta do tema.

Os cadernos da edição de 2014 apresentavam a Matemática estruturada sobre cinco eixos: Números e operações; Pensamento Algébrico; Espaço e forma; Grandezas e Medidas e Tratamento da informação. Essa organização apresentava uma primeira mudança na proposta oficial para o ensino de Matemática nos anos iniciais, constante nos Parâmetros Curriculares Nacionais, nos quais a Matemática era apresentada em quatro blocos de conteúdos, sendo a mudança mais significativa, a proposição do eixo sobre o pensamento algébrico.

O material distribuído para os supervisores, formadores, orientadores e professores alfabetizadores, a fim de subsidiar a discussão sobre Alfabetização Matemática, totalizaram 12 cadernos, sendo eles: Caderno de Apresentação, Educação Matemática do Campo, Educação Inclusiva, Organização do Trabalho Pedagógico (caderno 1), Quantificação, Registros e Agrupamentos (caderno 2), Construção do Sistema de Numeração Decimal (caderno 3), Operações na Resolução de Problemas (caderno 4), Geometria (caderno 5),Grandezas e Medidas (caderno 6), Educação Estatística (caderno 7), Saberes Matemáticos e outros campos do saber (caderno 8) e Jogos na Alfabetização Matemática. Há, ainda, um livro com encarte de jogos para serem utilizados com os alunos.

\subsection{O PNAIC 2014 na UFPel}

No ano de 2014 as formações do PNAIC no RS ficaram a cargo de duas Instituições de Ensino Superior, a Universidade Federal de Santa Maria (UFSM) e a Universidade Federal de Pelotas (UFPel). 
A UFPel ficou responsável pela formação de 469 orientadores de estudos e aproximadamente 9000 professoras alfabetizadoras de 147 cidades, tendo três polos de formação, Pelotas, Porto Alegre e Osório, sendo que a formação presencial dos dois últimos ocorria no mesmo local.

Para dar conta das formações a equipe da UFPel contava com um coordenador geral, dois coordenadores adjuntos, 5 supervisores, 19 formadores da área da linguagem e 13 formadores da área da Matemática, pois neste ano o MEC disponibilizou dois formadores por turma de orientadores de ensino. Todas as turmas deveriam contar com uma dupla de formadores, mas houve uma grande dificuldade na seleção de formadores da área de Matemática, devido a Matemática dos anos iniciais não ser trabalhada nas Licenciaturas de Matemática, bem como ser pouco desenvolvida nos cursos de Pedagogia.

A fim de organizar as formações presencias com os orientadores de estudo, ocorriam primeiramente reuniões entre os coordenadores e supervisores da IES, depois, em reuniões quinzenais, os formadores recebiam orientações dos temas que deveriam abordar, bem como sugeriam outros que julgassem importantes para o seu polo, deste modo começavam a elaborar seus planejamentos, os quais tinham um fio condutor, mas que respeitava as particularidades regionais de cada polo de formação.

Os encontros de formação contavam com estratégias formativas comuns, como a leitura deleite, relato de experiências, leituras/atividades de estudo e aprofundamento em grupo, discussão de textos com sistematização oral e escrita, atividade de elaboração e análise de diferentes materiais manipulativos, jogos e livros de literatura que pudessem contribuir para a aprendizagem dos conteúdos matemáticos.

Além disso a prática de formação da UFPel no PNAIC contava com a caderneta de metacognição e com o livro da vida, bem como com a biografia Matemática e a linha do Numeramento, que foram realizadas para dar início a discussão sobre Alfabetização Matemática. A seguir descrevo brevemente cada um dos recursos aqui apresentados.

A caderneta de metacognição é um instrumento individual, realizada pelos orientadores de estudo nos encontros de formação presencial com suas formadoras e também pelas Professoras Alfabetizadoras nos momentos de formação presencial com suas respectivas orientadoras. Essa prática favorece ao professor pensar sobre o que foi discutido no encontro e responder, em forma de texto, aos seguintes questionamentos: O que eu aprendi? Como eu aprendi? O que não entendi? Realizando assim uma escrita reflexiva sobre os temas discutidos nos encontros. No começo de cada encontro presencial, após a leitura deleite, algumas professoras faziam a leitura de seus apontamentos, o que suscitava discussões no 
grande grupo, a fim de sanar as dúvidas que a colega tinha, confirmar suas certezas ou até mesmo discordar do que havia escrito. Este era um momento rico de troca entre os pares. Essa atividade foi proposta a partir da leitura do texto de Damiani, Gil e Protásio (2006) conforme nos diz o material produzido para uso nas formações pela coordenadora adjunta, professora Marta Nörnberg - o referido texto traz uma experiência pedagógica de formação de professoras, baseado na metacognição como recurso formativo. Primeiramente houve uma grande resistência dos professores na realização dessa atividade, mas ao compreender seus objetivos de reflexão dos processos de ensino e de aprendizagem passaram a engajar-se nesse projeto e transformá-lo em um momento rico de aprendizagem para o grupo.

O livro da vida era realizado ao final de cada dia trabalhado e deveria conter uma aprendizagem ou momento significativo do grupo, expresso das mais diversas maneiras, era um trabalho coletivo. Para isso o início do registro se deu a partir de uma questão contida no caderno de formação continuada: Quais práticas formativas experimentadas favorecem ou privilegiam o desenvolvimento das habilidades importantes para a formação continuada, especialmente enquanto professores alfabetizadores? Esse recurso metodológico foi proposto tendo como referência o trabalho de Ruiz (2012) - como nos descreve a coordenadora adjunta do programa, Marta Nörnberg - o qual relata que o livro da vida é uma técnica de Célestin Freinet, cujo objetivo é o registro da livre expressão, no qual se relata acontecimentos vivenciados e experimentados no cotidiano.

A biografia Matemática era uma atividade baseada na proposta de Santos (2005), cujo objetivos, segundo a autora são oferecer ao aluno a oportunidade de se colocar e expor suas origens de formação, sua disponibilidade de tempo extraclasse e de delinear seu perfil. Para isso se propões duas indagações, uma sobre uma experiência positiva com a Matemática e a outra uma experiência negativa, onde deve ser feito primeiro com a positiva, pois as negativas podem bloquear as satisfações. No caso das orientadoras de estudo foi proposto uma reflexão sobre os conteúdos matemáticos que julgavam dominar e aqueles que precisariam estudar a fim de se sentirem seguras para ensinar.

A Linha do Numeramento consistia em propor às orientadoras de estudo um relato das experiências envolvendo a Matemática, desde sua infância até a vida adulta, com discussão e trabalhos em grupos e apresentação coletiva. Resgatando suas experiências, as professoras puderam perceber a importância de se trabalhar a Matemática voltada para a Alfabetização, além do papel social da Matemática e o quanto esse componente curricular está presente em nossas vidas mesmo antes de ingressarmos no ensino escolar. 
Os orientadores de ensino em suas formações com as professoras alfabetizadoras, foram orientados a utilizar os mesmos recursos metodológicos que foram realizados com eles, nos momentos de formação presencial: "Caderno de Metacognição; Livro da Vida; Coleta de produções conceituais; Memórias; Análise de jogos e materiais didáticos; Registros". Assim como utilizar os cadernos de formação como base da organização didática, através de leitura e discussão dos artigos contidos nos mesmos.

\section{Conclusões}

Através do PNAIC se propiciou um importante momento de formação continuada aos professores dos anos iniciais que, embora sem formação em Matemática, são professores que ensinam Matemática e, portanto, precisam de um aprofundamento tanto teórico quanto metodológico nesse campo que normalmente é trabalhado de maneira superficial nos cursos de Pedagogia.

A pesquisa em andamento pretende investigar junto às professoras polivalentes quais saberes o PNAIC produziu e que atualmente são por essas professoras mobilizados, para ensinar matemática aos seus alunos.

Como o trabalho encontra-se em construção, não há ainda conclusões definitivas, porém algumas questões já se apresentam de forma conclusiva.

Até o presente momento foram realizadas leituras sobre formação de professores, ensino de Matemática nos anos iniciais, sobre alfabetização matemática e o PNAIC.

As leituras realizadas indicam para a fundamental importância da formação matemática do professor que irá atuar nos anos iniciais, bem como evidenciam o baixo investimento dos cursos de formação inicial, decorrendo daí a necessidade de formação continuada para esses sujeitos. Espera-se com a pesquisa contribuir nesse debate tão importante.

\section{Referências}

BRASIL, Portaria n. 867 de 04 de julho de 2012. Institui o Pacto Nacional pela Alfabetização na Idade Certa a as ações do Pacto e define suas diretrizes gerais. Diário Oficial da União. Brasília, DF, 5 jul. de 2012. Disponível em: <http://download.inep.gov.br/educacao_basica/provinha_brasil/legislacao/2013/portari a_n867_4julho2012_provinha_brasil.pdf>. Acesso em: 20 jun 2017

CURI, Edda. A Matemática e os Professores dos anos iniciais. São Paulo: Musa Editora, 2005. 
MANRIQUE, Ana Lúcia e ANDRÉ, Marli. Relações com saberes na formação de professores. In: NACARATO, Adair Mendes e PAIVA, Maria Auxiliadora Vilela (org.). A formação do professor que ensina Matemática: perspectivas e pesquisas. 3. Ed. Belo Horizonte: Autêntica, 2013.

MORAES, Roque e GALIAZZI, Maria do Carmo. Análise textual discursiva: processo reconstrutivo de múltiplas faces. In Ciência \& Educação, v. 12, n. 1, p. 117-128, 2006.

MIZUKAMI, Maria das Graças Nicoletti. Aprendizagem da docência: conhecimento específico, contextos e práticas pedagógicas. In: NACARATO, Adair Mendes e PAIVA, Maria Auxiliadora Vilela (Org.). A formação do professor que ensina Matemática: perspectivas e pesquisas. 3. Ed. Belo Horizonte: Autêntica, 2013. 